\title{
Effect of Track Overlap on the Microstructure and Properties of the CoCrMoSi PTA Coatings
}

\author{
Rafael Guetter Bohatch ${ }^{a}$, Karin Graf ${ }^{b}$, Adriano Scheid ${ }^{\text {* }}$ \\ ${ }^{a}$ Programa de Pós-Graduação em Engenharia Mecânica - PGMec, Universidade Federal do \\ Paraná-UFPR, Curitiba, PR, Brazil \\ ${ }^{b}$ Departamento de Engenharia Mecânica, Universidade Federal do Paraná - UFPR, \\ Curitiba, PR, Brazil
}

Received: October 16, 2014; Revised: May 1, 2015

\begin{abstract}
Broadly speaking, the research and design of coatings are generally studied by way of single-track deposits; otherwise, the development of a coated part entails the understanding of how multi-track welding influences the microstructure and properties of the surface. This study evaluated the effect of track overlap on the microstructure and properties of the CoCrMoSi Tribaloy T400 alloy coatings produced on AISI 316L steel substrate. The characterization was performed by scanning electron microscopy, hardness and X-ray diffraction. The correlation between the degree of overlap and performance of the coatings was assessed by wear tests. The single track deposits showed hypoeutectic microstructure as a result of high Iron, Chromium and Nickel content. From the second track on, the chemical composition was displaced back to eutectic and then to hypereutectic with overlap of 25 and $50 \%$, respectively. The microstructure dictated the hardness of the coatings $\left(527-701 \mathrm{HV}_{0.5}\right)$ and the lower mass loss rate was measured for hypereutectic with primary Laves phase.
\end{abstract}

Keywords: CoMoCrSi alloy, plasma transferred arc, dilution, track overlapping, microstructure, wear behavior

\section{Introduction}

Different processes are used to produce coatings and the techniques which promote metallurgical bonding affect the microstructure features of alloys. In light of this, understanding the correlation among processing, microstructure and mechanical properties of the CoCrMoSi alloy coatings can be a challenge. A recent review of Plasma Transferred Arc (PTA) has pointed out the features that make the technique important and a potential solution for processing special alloys, due to the microstructure control and refinement of produced deposits ${ }^{1}$.

Cobalt, Nickel and Iron-based superalloys are recognized as being able withstand harsh environments, involving wear, corrosion and corrosion-wear. Co-based alloy coatings have been applied to improve the service life of different components like valves and valve seats, bearings and bushings, sleeves, dies and punches. The high corrosion resistance of Cobalt-based alloys is related to Chromium content which also acts as a solid solution strengthener ${ }^{2}$. However, when wear and corrosion are concurrent, the deleterious effect is usually synergic, requiring special alloys ${ }^{3,4}$.

The CoCrMoSi alloy system has shown better results under wear and corrosion-wear environments compared to carbides reinforced Co-based alloys. The superior performance is attributed to the presence of the hard intermetallic Laves phase in a lamellar eutectic and/or primary phase on the microstructure of the alloys (Laves phase is the Co, Mo

*e-mail: scheid@ufpr.br and Si close-packed hexagonal (hcp) compound that can develop as $\mathrm{Co}_{3} \mathrm{Mo}_{2} \mathrm{Si}$ and/or CoMoSi) $)^{5,6}$.

Even though better wear and corrosion-wear results are observed due to the presence of the Laves phase, the low ductility and toughness of the alloys still limit many applications. Processing is also a challenge because of microstructure of the alloy is comprised of a large fraction of the hard Laves phase $e^{7-9}$. Decreasing the Silicon and Molybdenum content on cast CoCrMoSi alloys seems to be a good way to reduce the hard phase volume fraction, thus improving the ductility and toughness ${ }^{8,9}$.

The production of welded coatings must consider the interaction between the deposition alloy and the substrate, as higher dilution induces lower hardness of the coatings. This reduction in hardness has been attributed to several factors, including the participation of the chemical elements (such as iron, chromium and nickel) from the steel substrates ${ }^{10-12}$. Coatings are largely studied by way of dilution on single track deposits processed with different deposition current ${ }^{10,11}$. However, limited data are available regarding the processing of coated areas that require track overlap.

This study therefore evaluated CoCrMoSi alloy coatings in order to establish the correlation between the degree of track overlap on the PTA processing and the coatings features. To that end, single and multiple tracks were produced with 25 and $50 \%$ overlapping. Based on experimental results, the influence of overlapping degree on the microstructure, hardness and wear performance of the coatings was assessed. 


\section{Material and Methods}

Atomized CoCrMoSi alloy with particle size ranging between $90-150 \mu \mathrm{m}$ was deposited, as shown in Table 1. Single track with $100 \mathrm{~mm}$ length was processed on AISI 316L stainless steel substrate with thickness of $12.5 \mathrm{~mm}$, as seen in Table 2. The extremities $(20 \mathrm{~mm})$ were discarded and the characterization was carried out in the middle of track length.

First track coatings were evaluated concerning track geometry and dilution, seen in Figure 1a. The interaction with the substrate (dilution) was determined on the transverse cross-section by the ratio between the melted area of the substrate and the total melted area. Multiple tracks were processed with 25 and $50 \%$ overlapping to produce coated areas of $100 \times 50 \mathrm{~mm}$, as illustrated in Figure $1 \mathrm{~b}$ and Figure 1c. The overlap displacement was determined by way of width of the first track and overlapping procedure considered the expression:

$\mathrm{D}_{\mathrm{O}}=((100-\mathrm{O}) / 100) * \mathrm{~W}$

Where: $\mathrm{D}_{\mathrm{O}}$ is the lateral linear displacement of overlapping $(\mathrm{mm}), \mathrm{O}$ is the overlapping (\%) and $\mathrm{W}$ is the width ( $\mathrm{mm})$ of the first track deposit.
The description and volume fraction of the microstructure were performed by scanning electron microscopy on the transverse cross section and Olympus Soft Imaging Solutions ${ }^{\circledR}$ software. The phases were identified using X-ray diffraction (XRD) analysis on the top surface of the coatings with $\mathrm{K}_{\alpha} \mathrm{Cu}$ radiation from 20 to $120^{\circ}$ with $1 \mathrm{~s}$ time of exposure channel. Coatings hardness was measured on the transverse cross-section under $0.5 \mathrm{kgf}$ load and results as an average of 5 measurements.

Wear performance of CoCrMoSi coated areas (25 and $50 \%$ overlapping) were assessed by abrasive sliding tests. Pins measuring $4 \times 4 \mathrm{~mm}$ were cut out of the coatings and worn against silicon carbide paper (\#220) assembled on a $63 \mathrm{HRC}$ hardness metal disc, under $0.5 \mathrm{kgf}$ axial load and $1.5 \mathrm{~m} / \mathrm{s}$ tangential speed. Mass loss was measured by weighing pins before beginning tests and after each $250 \mathrm{~m}$ sliding distance up to $750 \mathrm{~m}$, at room temperature.

\section{Results and Discussion}

\subsection{Coatings integrity and track geometry}

A visual inspection of the coatings revealed a smooth surface without welding defects. The first track of CoCrMoSi coating processed with 180 A deposition current exhibited

Table 1. Chemical Composition of the PTA alloy powder and steel substrate.

\begin{tabular}{|c|c|c|c|c|c|c|c|c|c|}
\hline \multirow{2}{*}{ Alloy / Element } & \multicolumn{9}{|c|}{ Chemical Composition, wt\% } \\
\hline & Co & $\mathrm{Cr}$ & $\mathbf{W}$ & Mo & $\mathrm{C}$ & $\mathrm{Fe}$ & $\mathbf{N i}$ & $\mathbf{S i}$ & Mn \\
\hline $\mathrm{CoMoCrSi}-\mathrm{T} 400$ & Bal. & 8.8 & $\ldots$. & 29.1 & 0.05 & 0.4 & 0.6 & 2.4 & $\ldots$. \\
\hline \multirow{2}{*}{ Substrate } & \multicolumn{9}{|c|}{ Chemical Composition, wt\% } \\
\hline & $\mathbf{C}$ & Mn & $\mathbf{S i}$ & $\mathbf{P}$ & $\mathbf{S}$ & $\mathrm{Cr}$ & $\mathbf{N i}$ & Mo & Al \\
\hline AISI 316L & 0.02 & 1.35 & 0.43 & 0.03 & 0.01 & 16.78 & 10.12 & 2.13 & 0.002 \\
\hline
\end{tabular}

Table 2. PTA processing parameters.

\begin{tabular}{lcc}
\hline \multicolumn{1}{c}{ Parameters } & First Track & Multiple Tracks \\
\hline Shielding gas (1/min) & 2 & 2 \\
Protection gas (1/min) & 15 & 15 \\
Powder feeding gas (1/min) & 2 & 2 \\
Main arc current (A) & 180 & 180 \\
Powder feed rate & Constant in volume & Constant in volume \\
Travel speed (mm/min) & 100 & 100 \\
Distance torch / substrate (mm) & 10 & 10 \\
Electrode diameter (mm) & 3.125 & 3.125 \\
Overlapping & No & 25 and $50 \%$ \\
\hline
\end{tabular}

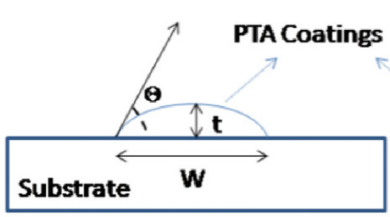

(a) First Track-No Overlapping

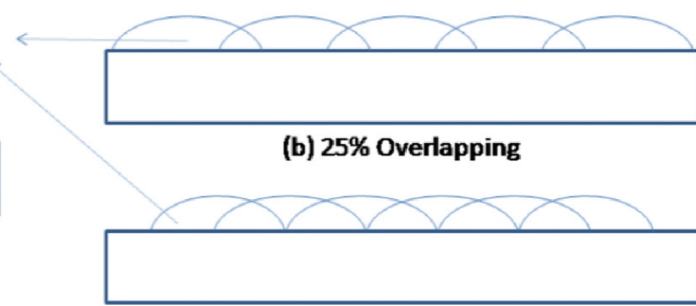

(c) $50 \%$ Overlapping

Figure 1. Schematic showing the processing of first track and coatings with 25 and $50 \%$ overlapping. 
$2.1 \mathrm{~mm}$ reinforcement thickness, $38^{\circ}$ wettability angle $(\Theta)$ and $12.0 \mathrm{~mm}$ track width, as shown in Table 3. The high wettability expressed by the low angle $\Theta$ and large width (W) indicates processing quality coated areas is feasible.

As can be seen in Equation 1, lateral linear displacement of 9 and $6 \mathrm{~mm}$ were used to produce coatings with 25 and $50 \%$ overlap $\left(\mathrm{D}_{\mathrm{O}}\right)$. Compared to the first track $(2.1 \mathrm{~mm})$, the reinforcement thickness $(\mathrm{t})$ of the coatings increased to 2.5 and $3.6 \mathrm{~mm}$ as overlapping ranged from 25 and $50 \%$. Since the coatings fusion line is continuous for overlapping conditions, the real reinforcement (or total thickness of Co-based layer) was measured by the distance between the fusion line and the top of coatings, reaching 3.0 and $4.0 \mathrm{~mm}$ (Table 3 ).

\subsection{Effect of track overlapping on the microstructure}

The expected hypereutectic microstructure comprised of primary Laves phase and eutectic lamellar with Laves phase and Cobalt solid solution observed on cast CoCrMoSi alloy T400 was not identified on the first track of the coatings 9 . On the contrary, hypoeutectic Cobalt solid solution dendrites and interdendrictic eutectic lamellar (Laves phase and Cobalt solid solution) microstructure was observed, as shown in Figure 2. The differences in the microstructure are attributed to the high dilution measured for the first track (38\%). It increased the amount of Iron, Chromium and Nickel on melting pool, changing therefore the chemical composition

Table 3. Geometry and dilution of deposited coatings.

\begin{tabular}{|c|c|c|c|c|}
\hline \multicolumn{5}{|c|}{ CoCrMoSi Alloy - Tribaloy T400 } \\
\hline \multirow[t]{3}{*}{ Substrate } & Evaluation & First Track & \multicolumn{2}{|c|}{ Coatings Multiple Tracks } \\
\hline & Overlapping & No & $25 \%$ & $50 \%$ \\
\hline & Parameter & $180 \mathrm{~A}$ & $180 \mathrm{~A}$ & $180 \mathrm{~A}$ \\
\hline \multirow[t]{7}{*}{ AISI 316L } & Dilution (\%) & 38 & 17 & 13 \\
\hline & Reinforcement thickness, $\mathrm{t}(\mathrm{mm})$ & 2.1 & 2.5 & 3.6 \\
\hline & Total Thickness (mm) & Not Applied & 3.0 & 4.0 \\
\hline & Width, W (mm) & 12.0 & \multirow{2}{*}{\multicolumn{2}{|c|}{ Not Applied }} \\
\hline & Wettability Angle, $\Theta\left({ }^{0}\right)$ & 38 & & \\
\hline & Track Number & 1 & 7 & 10 \\
\hline & Displacement on Overlapping (mm) & Not Applied & 9 & 6 \\
\hline
\end{tabular}
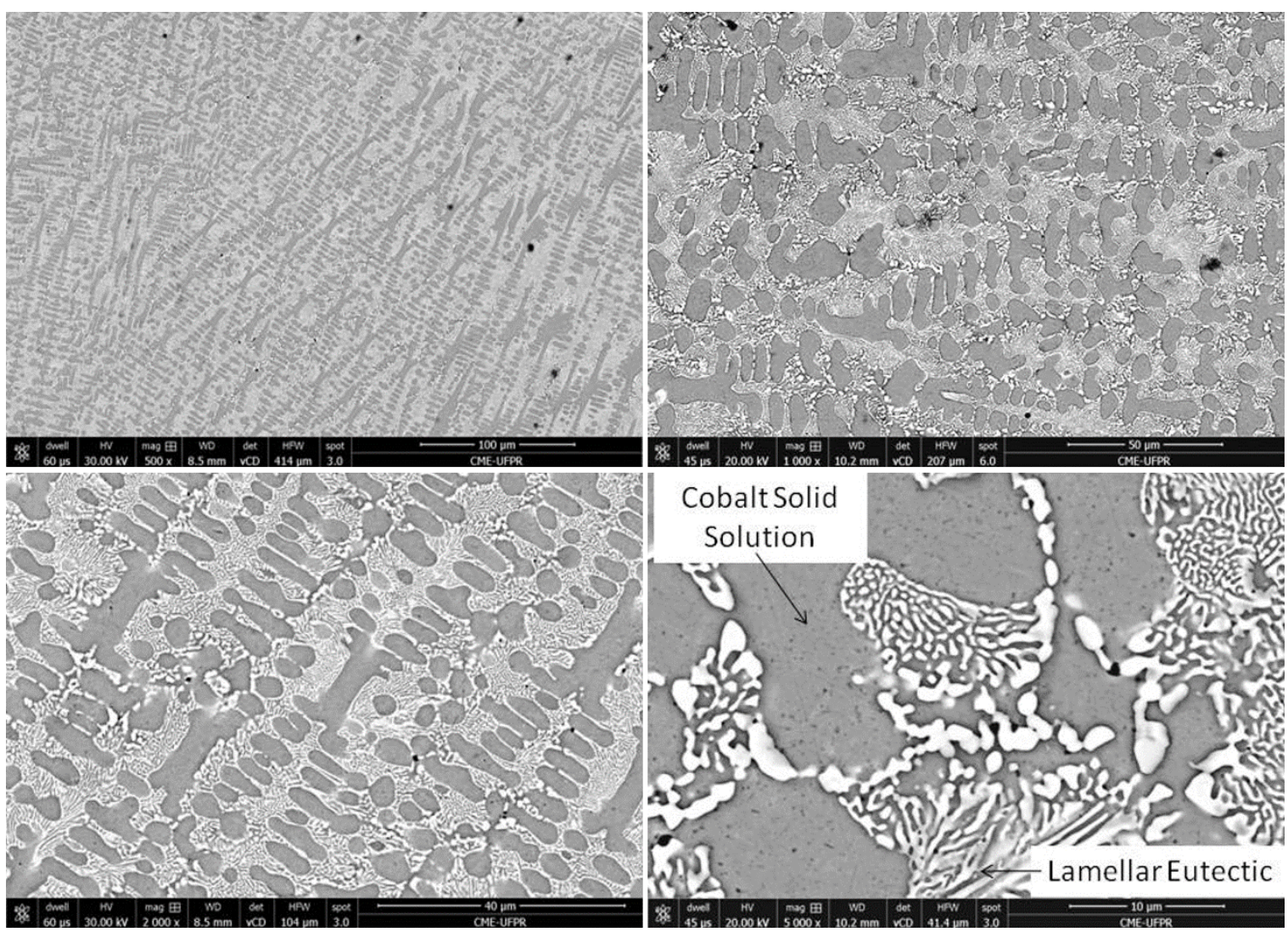

Figure 2. Hypoeutectic microstructure for first track of CoCrMoSi Coatings (180 A). 
of the coatings, resulting in hypoeutectic microstructure, as observed previously on newly developed cast alloy ${ }^{9,13}$.

The dilution of the multi-track coatings was measured considering the melted area of stainless steel substrate and total melted area. An average dilution of $17 \%$ and $13 \%$ was measured for 25 and 50\% track overlapping, respectively (Table 3). Compared with the first track, the dilution decreased 55 and $66 \%$, confirming the direct dependence between dilution and track overlap degree. Once the overlapping induces dilution to decrease, the microstructure of the coatings is expected to change.

From the second track on, not just the stainless steel substrate melts but also the prior track, reducing then the amount of Iron, Chromium and Nickel on melting pool, changing the microstructure. Fully lamellar eutectic microstructure (Laves phase and Cobalt solid solution) was observed for $25 \%$ overlapping and a hypereutectic for $50 \%$ overlapping, as shown in Figure 3 and Figure 4, respectively. The lower dilution of $50 \%$ overlapping led to hypereutectic microstructure comprised of primary Laves phase and eutectic lamellar, as reported on cast CoCrMoSi alloy T400 ${ }^{[9]}$.

Phase quantification indicated that the microstructure of the first track is comprised of 54\% interdendrictic eutectic lamellar and 46\% Cobalt solid solution dendrites. From the second track, the coatings with $25 \%$ overlapping showed microstructure $100 \%$ eutectic lamellar and the coatings with $50 \%$ overlapping presented $84 \%$ eutectic with $16 \%$ primary Laves phase, as seen in Figure 5.
Despite pronounced differences on the microstructure of the coatings, the main phases formed did not change. Cobalt solid solution (FCC) and Laves phase CoMoSi and $\mathrm{Co}_{3} \mathrm{Mo}_{2} \mathrm{Si}$ were observed for coatings, suggesting the measured dilution does not affect the developed phases but their volume fraction and distribution, as can be seen in Figure $6^{[5,9,12]}$.

Several studies have been carried out in order to improve CoCrMoSi T400 cast alloy ductility by way of the reduction of Molybdenum and Silicon alloying contents. As a result, the reduced volume fraction of Laves phase led to better ductility on cast alloys. Otherwise, the microstructure of the coatings depended directly on the track overlap. Since the microstructure varied from hypo to hypereutectic and different fraction of hard Laves phase was observed, the ductility of the coatings can be controlled and therefore better designed.

\subsection{Coatings interface}

The degree of interaction with the substrate and prior track altered the microstructure of the coatings. This section therefore provides details of the microstructure at the fusion line between tracks and track with steel substrate.

For the first track, the interface between coatings and stainless steel substrate showed an initial planar growth from 5 to $20 \mu \mathrm{m}$, as a continuous layer of Cobalt solid solution (Co SS). As the temperature on melting pool decreased, a Cobalt solid solution (Co-SS) columnar dendrictic narrow region was observed. Finally, a hypoeutectic microstructure
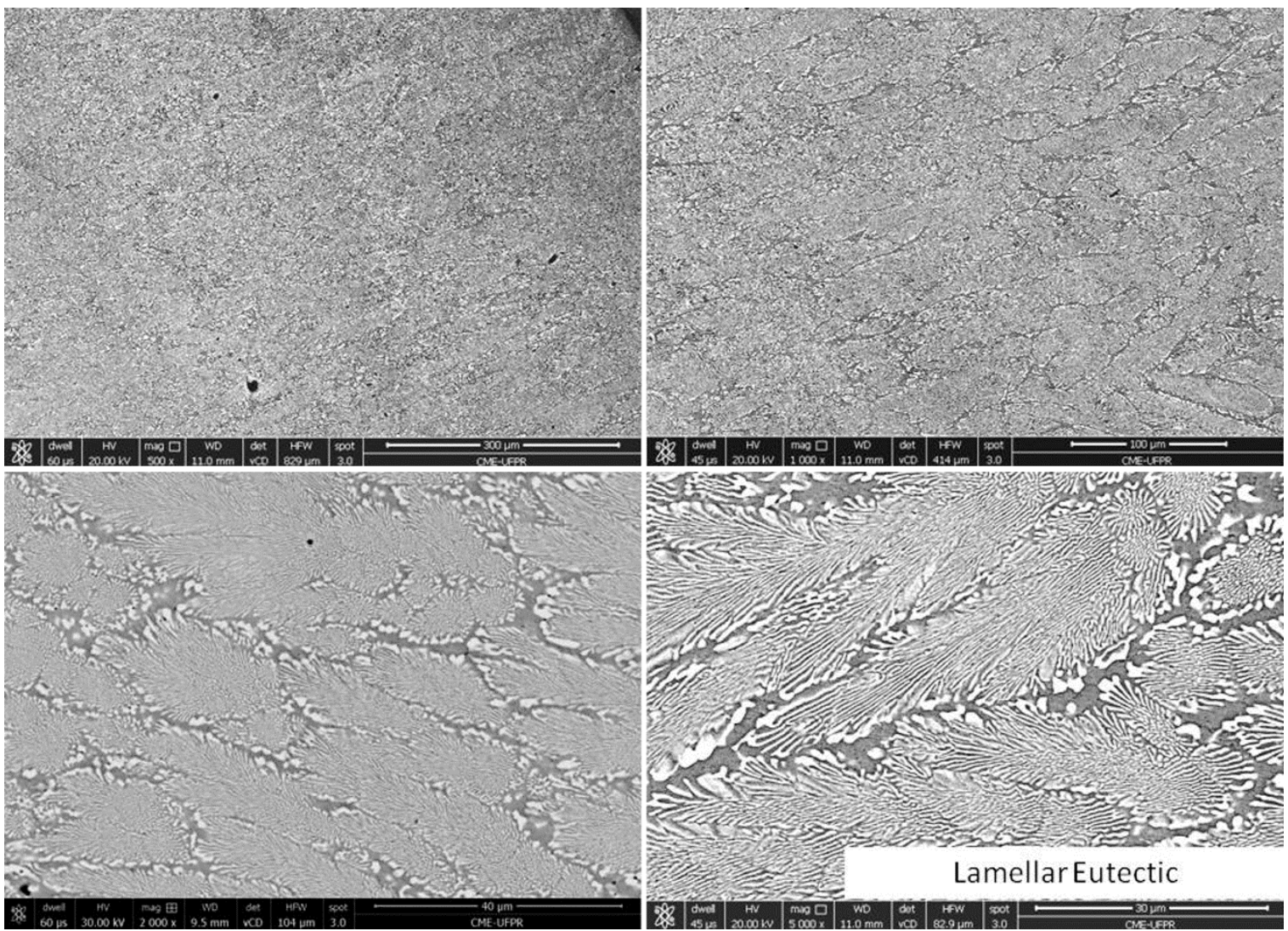

Figure 3. Eutectic microstructure of PTA CoCrMoSi coating with $25 \%$ overlapping degree (180 A). 

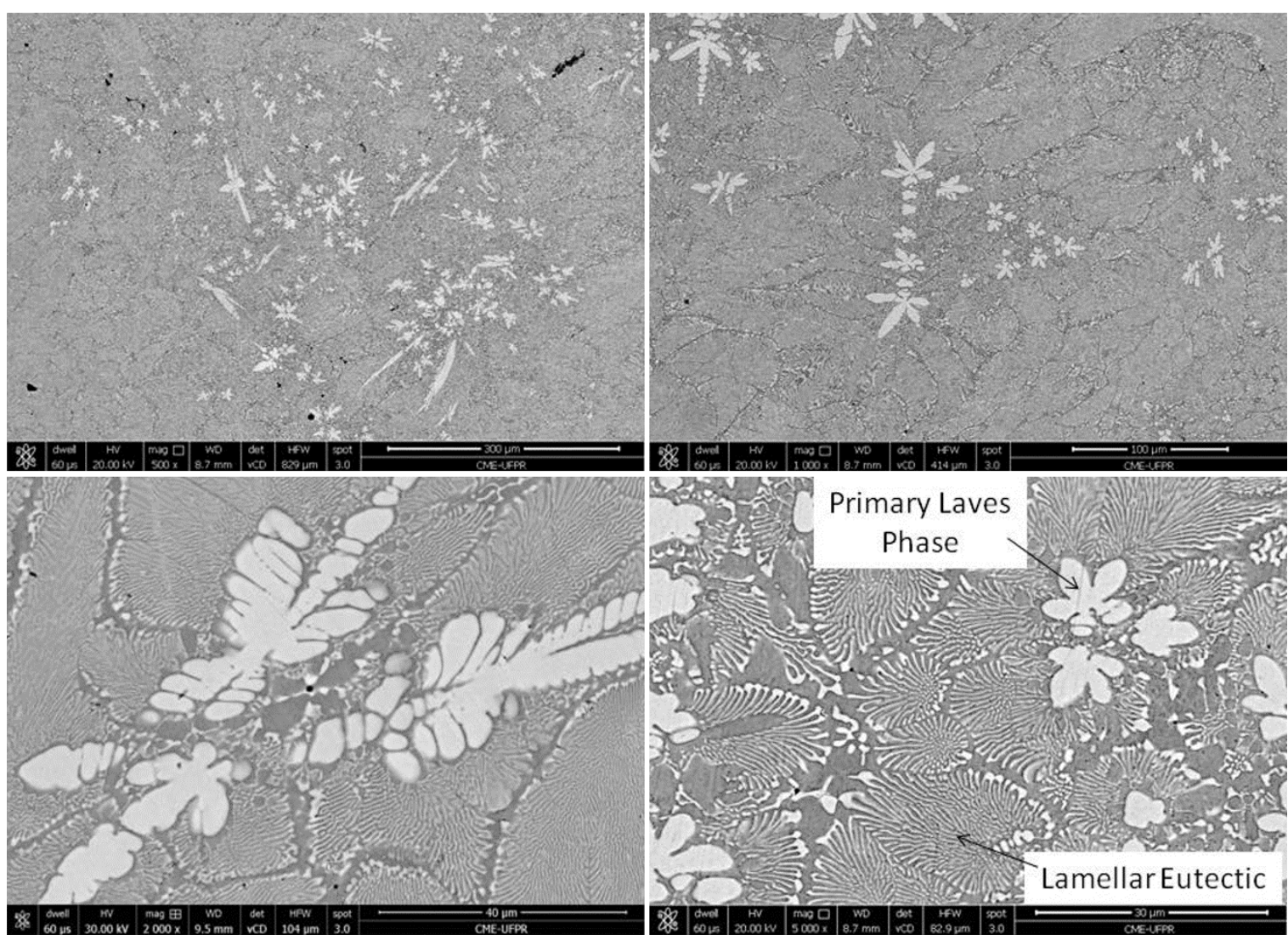

Figure 4. Hypereutectic microstructure of PTA CoCrMoSi coating with 50\% overlapping degree (180 A).

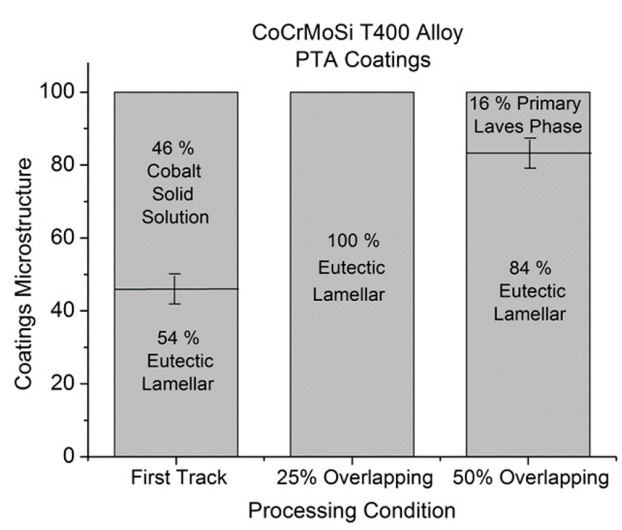

Figure 5. Effect of processing on coatings microstructure.

of Cobalt solid solution dendrites and interdendrictic eutectic lamellar was identified among the bulk of the coatings, as seen in Figure $7 \mathrm{a}$ and Figure 8a, as a result of the higher amount of Iron, Chromium and Nickel near the interface.

For the second track on, for $25 \%$ and $50 \%$ overlapping degrees, the initial Cobalt solid solution planar growth was observed again, as well as an ensuing narrow columnar growth reaching a thickness of up to $100 \mu \mathrm{m}$. Furthermore, as constitutional undercooling increases and dilution decreases, two distinct microstructures were observed on the bulk of the coatings: lamellar eutectic for $25 \%$ overlapping degree and primary Laves phase in a lamellar eutectic for $50 \%$ overlapping. The planar growth observed and heretofore undescribed can be of relevance to reduction of the hardness gradient between substrate and T400 coatings.

With regard to the analysis of the interface between tracks, a coarsened Laves phase with spheroid shape within a eutectic was formed at the heat-affected zone, irrespective of overlapping degree. This microstructure extended from 500 to $800 \mu \mathrm{m}$ thick, starting on the fusion line toward the top of the coatings for 25 and $50 \%$ overlapping, as can be seen in Figure 9 and Figure 10. The thermal cycle due to successive welding passes induced Laves phase coarsening at inter-track heat-affected zone. This behavior was also observed on aging tests at $1000^{\circ} \mathrm{C}$ for T400 alloy PTA coatings ${ }^{14}$ and for laser cladding coatings ${ }^{8}$.

\subsection{Microstructure effect on hardness and wear performance}

Co-based CoCrMoSi alloys are intermetallic reinforced materials and chemical composition is reported as the most important factor dictating volume fraction of Laves phase and, therefore, hardness and wear behavior ${ }^{9,12,14}$. Since overlapping degree induced different interaction with the substrate causing microstructure to change, significant differences on coatings performance is likewise expected.

Indeed, the first observation that can be made is, the higher the interaction with the substrate, the lower the coatings hardness due to the reduction of Laves phase volume 


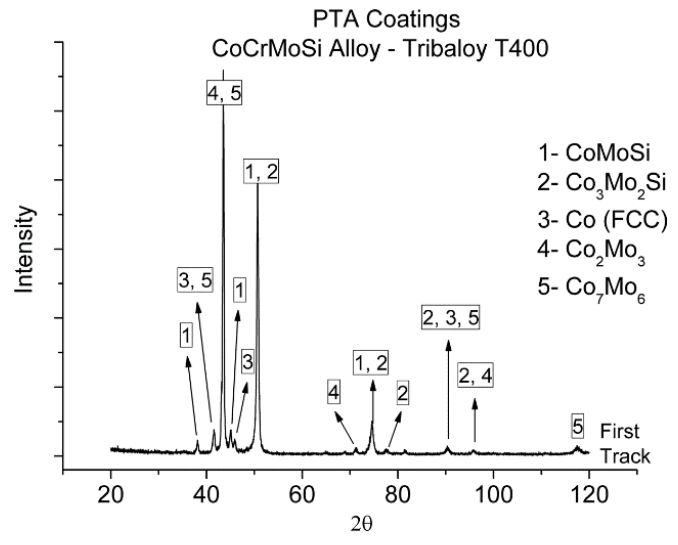

(a)

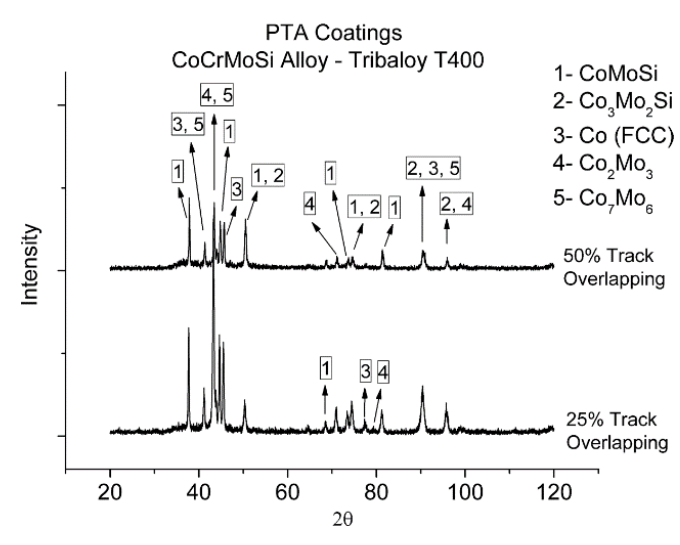

(b)

Figure 6. Developed phases on CoCrMoSi alloy coatings: (a) First Track and (b) Coatings.

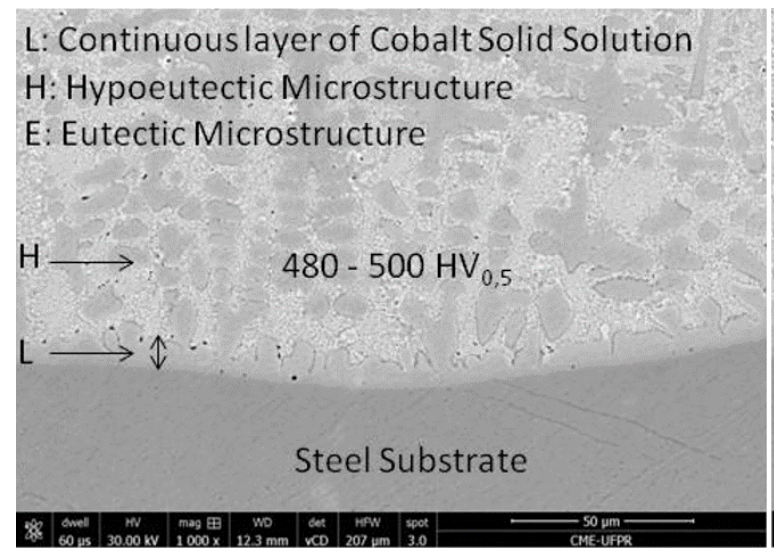

(a)

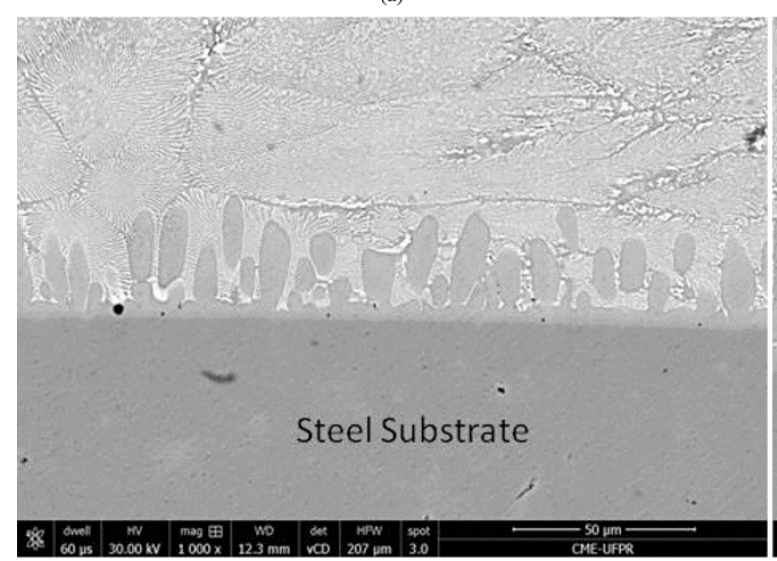

(c)

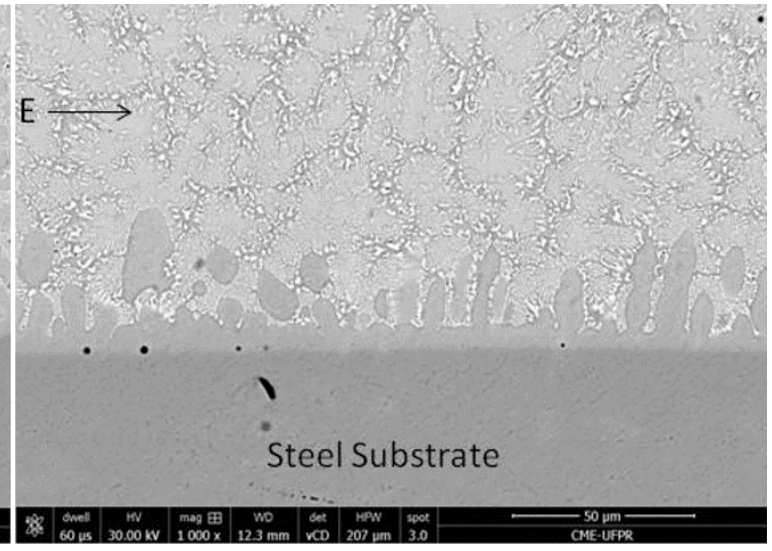

(b)

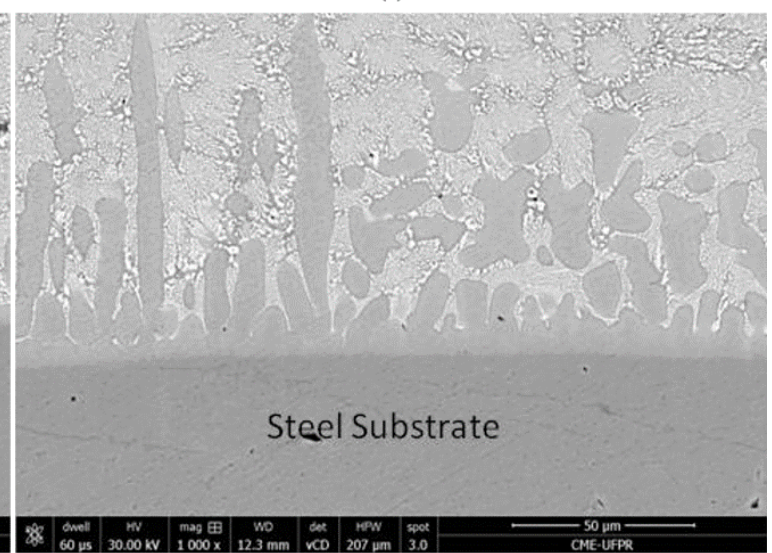

(d)

Figure 7. Microstructure between Coatings and Steel Substrate for $25 \%$ overlapping: (a) First track, (b) Second track, (c) Third track and (d) Fifth track.

fraction (Figure 11). The lowest hardness $\left(527 \mathrm{HV}_{0.5}\right)$ was observed for the highest dilution which occurred on first track (or single track) deposits. The hypoeutectic solidification promoted lower volume fraction of Laves phase and lower amount of Cobalt solid solution alloying, as previously reported by literature $8,9,12$.
A second observation is the higher track overlap, the higher the hardness of the coatings due to dilution decrease. In this way, the hardness reached 643 and $701 \mathrm{HV}_{0.5}$ for the coatings deposited with 25 and $50 \%$ overlapping, respectively. The observed microstructure and phase distribution, as well as the measured hardness are consistent with what has been predicted in the literature ${ }^{9,12,14}$. 


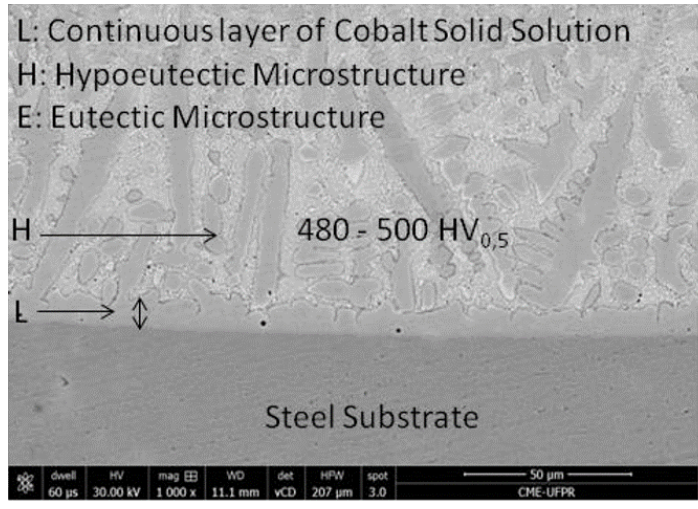

(a)

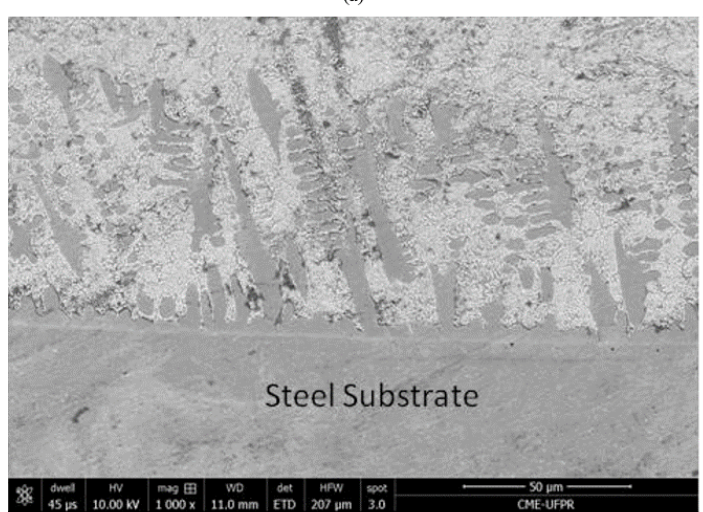

(c)

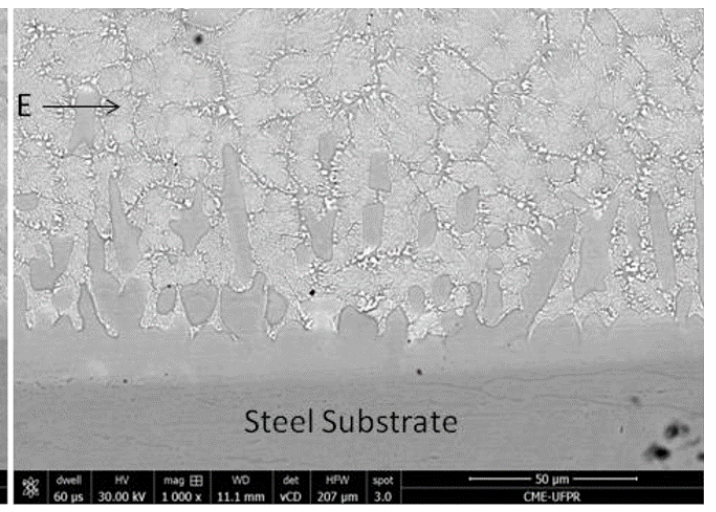

(b)

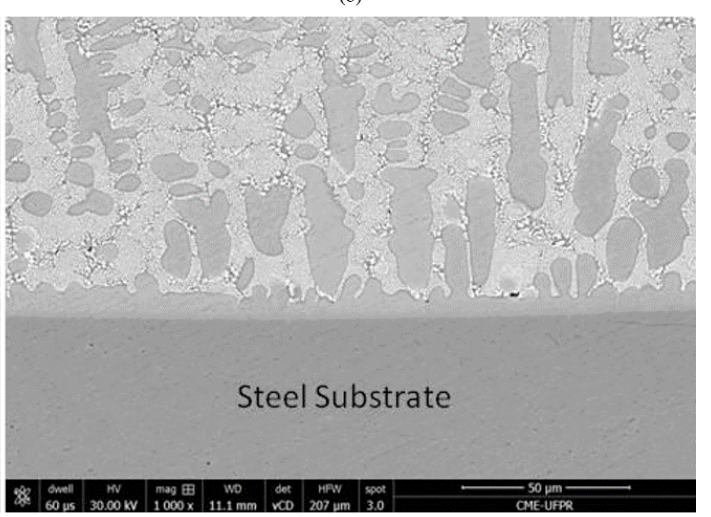

(d)

Figure 8. Microstructure between Coatings and Steel Substrate for 50\% overlapping: (a) First track, (b) Second track, (c) Third track and (d) Fifth track.
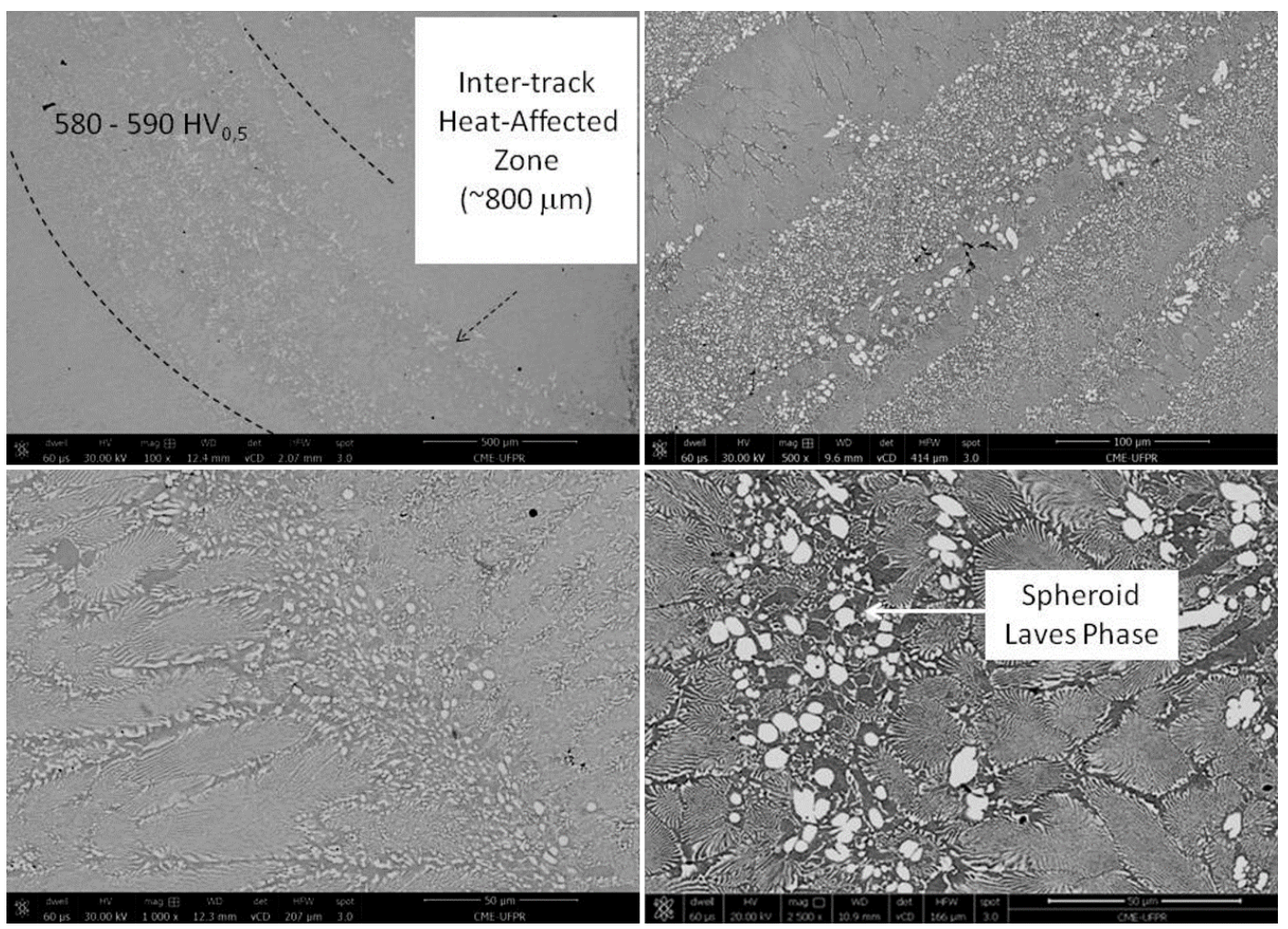

Figure 9. Spheroid Laves phase on inter-track heat-affected zone: $25 \%$ overlapping. 

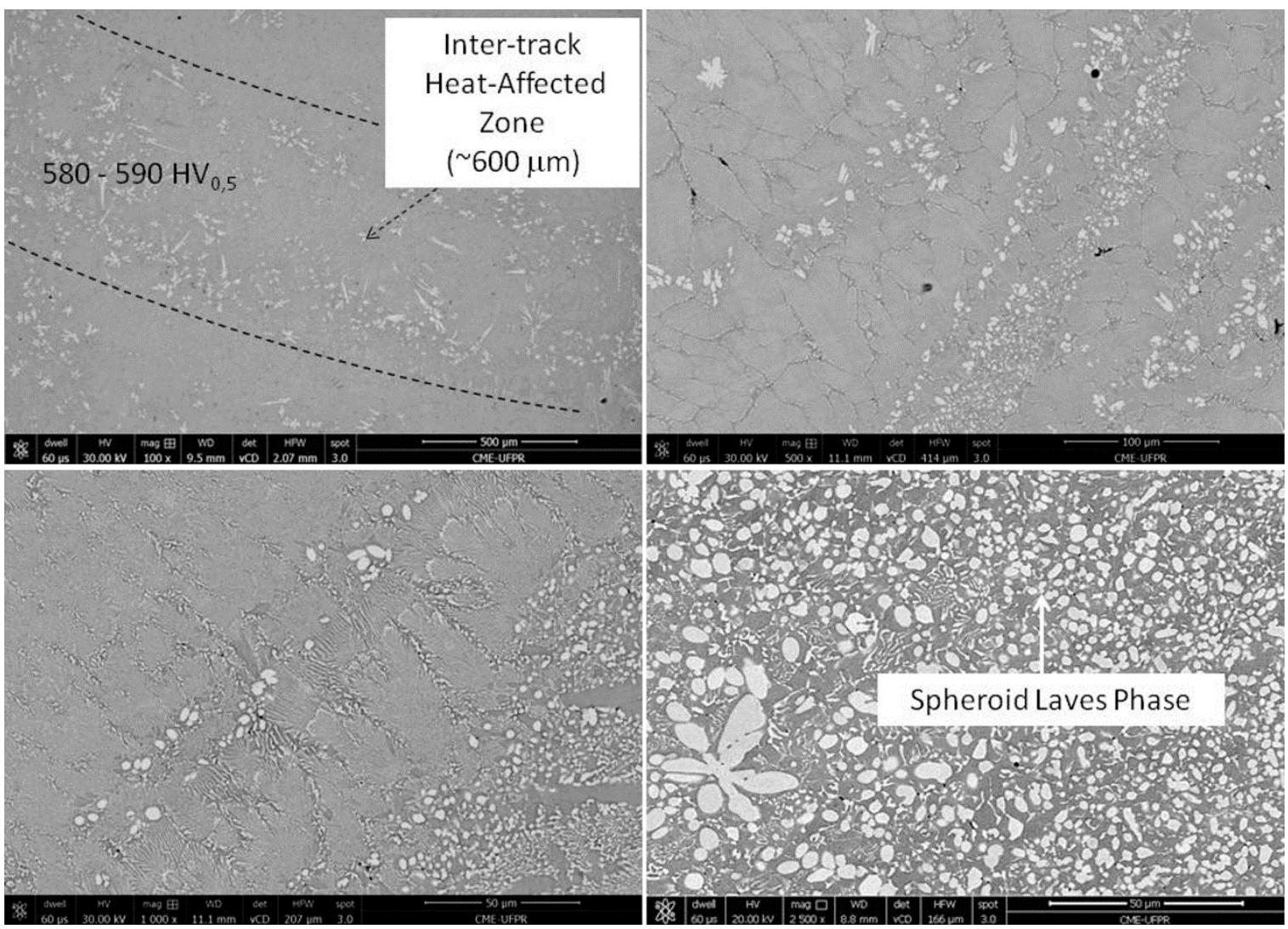

Figure 10. Spheroid Laves phase on inter-track heat-affected zone: $50 \%$ overlapping.

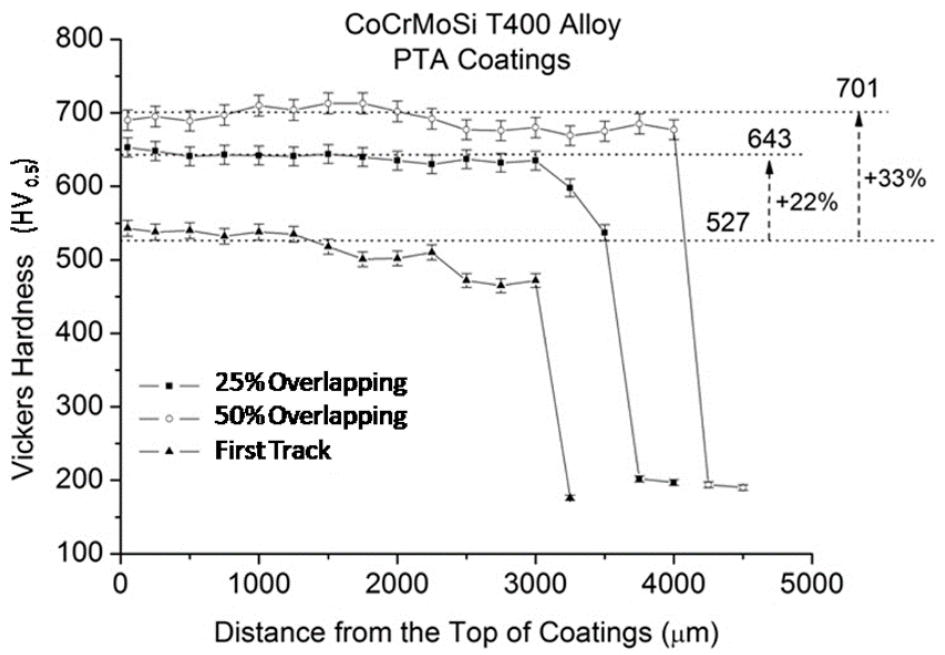

Figure 11. Hardness profile of first track and coatings.

The hardness at the interface among tracks and steel substrate ranged from 480 and $500 \mathrm{HV}_{0.5}$, following the trend for hypoeutectic microstructure induced by higher Iron, Chromium and Nickel content. Otherwise, inter-track heataffected zone showed hardness decrease, ranging from 580 $-590 \mathrm{HV}_{0.5}$, as a result of Laves phase coarsening, following the hardness reported previously for aged microstructures ${ }^{13}$.

The wear performance of the coatings was evaluated by way of abrasive sliding tests and reported as wear mass loss rate. The lower wear coefficient of $0.146 \mathrm{mg} / \mathrm{m}$ was obtained for hypereutectic microstructure of coatings $(50 \%$ overlapping) in accordance with literature of such cast alloys 5 , ${ }^{14}$. Higher wear coefficients were measured for hypoeutectic first track $(0.275 \mathrm{mg} / \mathrm{m})$ and for eutectic microstructure of coatings produced with $25 \%$ overlap $(0.187 \mathrm{mg} / \mathrm{m})$, as shown in Figure 12a.

Important differences in mass loss coefficient was measured, reaching $28 \%$ increase since primary Laves 


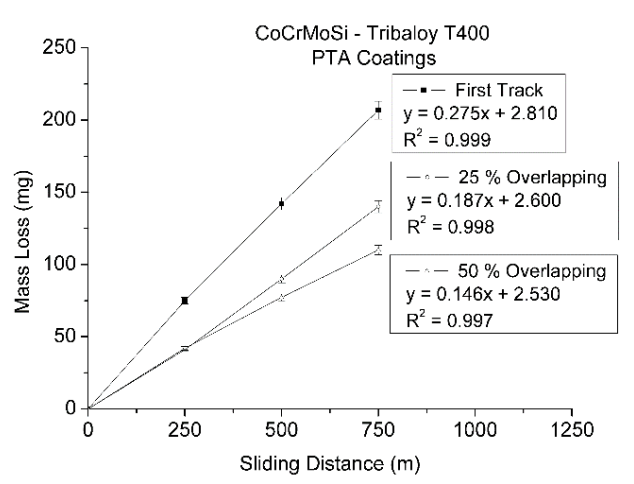

(a)

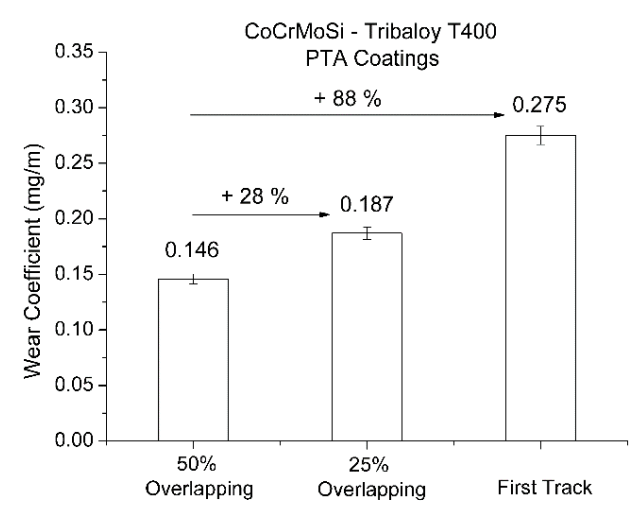

(b)

Figure 12. Wear behavior of CoCrMoSi alloy coatings: (a) wear curves and (b) Mass loss rate.

phase was suppressed by $25 \%$ overlapping and $88 \%$ increase for hypoeutectic first track, as seen in Figure $12 \mathrm{~b}$. Higher overlapping led the chemical composition back to hypereutectic with primary Laves phase, resulting in higher hardness and better wear performance. Results revealed the effect of track overlap on the microstructure and properties of CoCrMoSi alloy coatings by PTA because it significantly altered the dilution with the substrate.

\section{Final Remarks}

This study analyzed the influence of overlapping on the microstructure and properties of the PTA CoCrMoSi coatings. The main contributions presented are as follows:

- Track Overlap significantly altered the dilution with the substrate and, therefore, the microstructure of the CoCrMoSi coatings. The higher dilution observed for $25 \%$ overlapping induced the suppression of the

\section{References}

1. Silva RHG and Dutra JC. PTA-P process - a literature review as basis for innovations. Part 1 of 2: constructive elements. Soldagem \& Inspeção. 2012. http://dx.doi.org/10.1590/S010492242012000100011.

2. Donachie MJ and Donachie SJ. Superalloys: a technical guide. 2nd ed. Ohio: ASM International; 2002.

3. Kim H, Yoon B and Lee C. Sliding wear performance in molten $\mathrm{Zn}-\mathrm{Al}$ bath of cobalt-based overlayers produced by plasma transferred arc weld-surfacing. Wear. 2003; 254(5-6):408-414. http://dx.doi.org/10.1016/S0043-1648(03)00186-8.

4. Hou QY, Gao JS and Zhou F. Microstructure and wear characteristics of cobalt-based alloy deposited by plasma transferred arc weld surfacing. Surface and Coatings Technology. 2005; 194(23):238-243. http://dx.doi.org/10.1016/j.surfcoat.2004.07.065.

5. Scheid A and Oliveira ASCM. Analysis of PTA hardfacing with CoCrWC and CoCrMoSi alloys. Soldagem \& Inspeção. 2013; 18(4):322-328. http://dx.doi.org/10.1590/S010492242013000400004 .

6. Cakmak E, Tekin KC and Malayoglu U. Tribocorrosion of stellite 706 and tribaloy 400 superalloys. Tribology. 2010; $4(1): 8-14$. primary Laves phase, changing the microstructure to a full eutectic.

- The highest amount of Iron, Chromium and Nickel dictated the hypoeutectic microstructure at the interface between coatings and steel substrate. Otherwise, the inter-track heat-affected zone presented coarsened spheroid Laves phase as a result of welding thermal cycle. Thus, either chemical composition or thermal cycle affected the microstructure and hardness homogeneity of the coatings.

- Overlapping did not change the formed phases but enabled controlling Laves phase fraction and distribution. The overlap altered the hypoeutectic microstructure of the single track to eutectic and then to hypereutectic. The degree of overlap also influenced the hardness and wear properties of the coatings, mainly because of high impact on the amount of Laves phase.

7. Gao F, Liu R and Wu XJ. Triballoy alloy reinforced tin-bronze composite coating for journal bearing applications. Thin Solid Films. 2011; 519(15):4809-4817. http://dx.doi.org/10.1016/j. tsf.2011.01.035.

8. Przybylowicz J and Kusinski J. Laser cladding and erosive wear of Co-Mo-Cr-Si coatings. Surface and Coatings Technology. 2000; 125(1-3):13-18. http://dx.doi.org/10.1016/S02578972(99)00563-0.

9. Liu R, Xu W, Yao MX, Patnaik PC and Wu XJ. A newly developed Tribaloy alloy with increased ductility. Scripta Materialia. 2005; 53(12):1351-1355. http://dx.doi.org/10.1016/j. scriptamat.2005.08.033.

10. Antoszczyszyn TJ, Paes RMG, Oliveira ASCM and Scheid A. Impact of dilution on the microstructure and properties of Ni-based 625 alloy coatings. Soldagem \& Inspeção. 2014; 19(2):134-144. http://dx.doi.org/10.1590/0104-9224/SI1902.05.

11. Paes RMG and Scheid A. Effect of deposition current on microstructure and properties of CoCrWC alloy PTA coatings. Soldagem \& Inspeção. 2014; 19(3):247-254. http://dx.doi. org/10.1590/0104-9224/SI1903.07.

12. Scheid A and Oliveira ASCM. Effect of processing on microstructure and properties of CoCrMoSi alloy. Materials Research. 2013; 16(6):1325-1330. http://dx.doi.org/10.1590/ S1516-14392013005000120. 
13. Xu W, Liu R, Patnaik PC, Yao MX and Wu XJ. Mechanical and tribological properties of newly developed Tribaloy alloys. Materials Science and Engineering A. 2007; 452-453:427-436. http://dx.doi.org/10.1016/j.msea.2006.10.088.
14. Scheid A and D'Oliveira ASCM. Influence of aluminum on the microstructure of Co based alloy coatings. International Heat Treatment and Surface Engineering. 2011; 5(2):83-87. http:// dx.doi.org/10.1179/174951411X13051201040875. 